\title{
La arquitectura efímera y la transformación del espacio urbano. Algunos casos españoles entre 2016 y 2018
}

The ephemeral architecture and the transformation of the urban space. Some Spanish cases between 2016 and 2018

Carmen Flores Hurtado

Historia del Arte, Universidad de Málaga, España (cfloresh24@gmail.com)

Recibido el 31 de julio de 2018; revisado el 13 de agosto de 2018; aceptado el 29 de agosto de 2018; publicado el 13 de septiembre de 2018

RESUMEN: El arte efímero ha comenzado, en los últimos años, a habitar el entorno urbano más que en toda la historia. Ha tomado las calles con la intención de transformar el espacio público y de interactuar con la sociedad. Dentro de esto, la arquitectura efímera toma el protagonismo, pues se convierte en un motor fundamental para la creación de reflexiones en torno a las nuevas formas de expresión, y permite replantearse la noción de arquitectura tradicional. Lo efímero se fusiona con la ciudad y ambos dan lugar a un espacio accesible e inclusivo.

PALABRAS ClAVE: Arte efímero, Espacio público, Espacio urbano, Arquitectura Efímera, Arquitectura tradicional.

\begin{abstract}
In recent years, the ephemeral art has begun to inhabit the urban environment more than ever. He has taken to the streets with the intention to transform public space and to interact with society. Whitin this, ephemeral architecture takes the role, becomes an essential engine for the creation of reflections on new forms of expression, and allows you to redefine the notion of traditional architecture. The ephemeral merges with the city and give rise to reachable and inclusive space.
\end{abstract}

KEYWORDS: Ephemeral Art, Public space, Urban space, Ephemeral architecture, Traditional architecture. 


\section{Introducción}

Desde hace varias décadas, y remontándonos aproximadamente a los años 60, el arte ha tomado la calle; ha invadido el espacio a través de las distintas formas de creación. En este tema, el arte efímero juega un papel fundamental, ya que ha ido desarrollándose, cada vez más, en los espacios públicos. Ha servido y sirve como herramienta para acercar la sociedad a las distintas formas de expresión artística, estableciendo una relación inclusiva.

Estas prácticas, que han tomado la calle y han salido dispuestas a transformar por un lapso de tiempo el paisaje urbano, son a menudo las conocidas arquitectura y escultura, aunque desde las últimas décadas del siglo pasado es normal encontrarse con representaciones en forma de performance, instalación o incluso las relacionadas con las nuevas tecnologías.

En el presente artículo se abordará el desarrollo que ha tenido la arquitectura efímera en el espacio público, más concretamente haciendo hincapié en diversos ejemplos acontecidos en ciudades españolas a lo largo de los dos últimos años. Además, se hará un breve recorrido por la historia de la arquitectura con cualidades efímeras, y cómo ésta ha ido evolucionando hasta ser lo que es hoy.

Así como ha evolucionado la misma arquitectura, lo ha hecho también el paisaje urbano, ya que ha ido adquiriendo nuevos usos a lo largo de los años. En el ámbito del arte efímero, la transformación e inclusión de éste se ha hecho cada vez más evidente, pues multitud de artistas han tomado ese camino por la facilidad que supone realizar obras con carácter temporal que pueden llevarle a un reconocimiento igual o mayor que las obras de carácter permanente.

En este ámbito, y dado el carácter efímero de las obras que se insertan en el medio urbano, todas ellas son recordadas a través de las imágenes, de las fotografías que son tomadas in situ para documentar el hecho allí acontecido. Aunque por lo general, el término efímero hace referencia a un pequeño periodo de tiempo, en muchas ocasiones se podrán encontrar ejemplos que, por una razón u otra, permanecen más tiempo en el lugar que el primeramente establecido.

El objetivo principal de este trabajo es el de demostrar la importancia que, hoy en día, tiene el arte efímero para el desarrollo de las ciudades y para el acercamiento del arte a la sociedad. Como objetivos secundarios podemos establecer varios: valorar el vínculo que surge entre arte y ciudad, analizar las relaciones establecidas entre la sociedad y el arte efímero a través de los ejemplos mencionados o conocer las nuevas formas de creación que se dan en el ámbito arquitectónico. 


\section{La transformación del paisaje urbano y su constante unión con el arte}

La ciudad, desde sus orígenes más remotos, ha contenido espacios donde desarrollar eventos artísticos. Desde los teatros hasta las plazas, que han ido evolucionando para acoger distintas formas de expresión, como en la etapa barroca con la creación de escenografías a pie de calle, o en el siglo XX, con el nacimiento de la performance y el arte de acción, donde el espacio urbano era tomado como soporte para el desarrollo de estas expresiones.

En cuanto al arte efímero, el que nos ocupa en este artículo, hay que señalar que su vínculo con la ciudad ha sido un poco más tardío. Concretamente en el ámbito europeo, y centrándonos en España, podemos decir que las manifestaciones de carácter efímero comenzaron a emerger en el siglo XVII, con la creación de arquitecturas y decorados efímeros que se instalaban en las calles de las ciudades, y que se realizaban, generalmente, con un carácter religioso o festivo (Hermoso, 2004: 139).

En la actualidad se ha conseguido estrechar la unión entre arte y ciudad, gracias al surgimiento de nuevas formas de expresión que han ido tomando más protagonismo desde mediados del siglo pasado. Las instituciones públicas han comenzado a recurrir a estas nuevas formas de creación para crear señas de identidad, como el caso de las conocidas "Noches en Blanco", donde, además de ejemplos de arquitectura efímera, se puede encontrar performance, escultura, intervención mural, vídeo mapping y un sinfín de formas de creación que, durante una noche al año, acercan a la población al arte.

Por tanto, gracias a la creación de eventos como este, la ciudad ha empezado a cobrar un nuevo sentido cuando es fusionada con el arte. Se convierte en un espacio de creación y convivencia, y vuelve a recobrar el significado que antaño tenía, pasando a ser algo más que una simple máquina de habitar y de trabajar, y transformándose en un espacio inclusivo e interactivo.

Actualmente, la mitad de la población mundial vive en ciudades. El modelo urbanístico concebido hoy en día se basa, sobre todo, en la economía y en los mecanismos impuestos por los grandes países del mundo (Gómez, 2004: 36). De esto surge la necesidad de reconquistar los espacios públicos y cambiar la noción de ciudad, para evitar que el entorno urbano se convierta en un mapa de calles transitables, vacías y sin ninguna otra función que servir como soporte para la población. 
Con la llegada del arte efímero, la ciudad ha conseguido recobrar su vida y convertirse en un lugar más accesible. Con el desarrollo de las plazas, calles y zonas verdes, éstas recobran más sentido, ya que en ellas se realizan eventos artísticos. Hablamos de una regeneración urbana gracias al arte; sobre todo a través de las propuestas que en los últimos años se están realizando en barrios y zonas conflictivas de todo el mundo. Colectivos de artistas como Boa Mistura ${ }^{1}$ han conseguido la inclusión de la población en zonas poco accesibles de las ciudades, llevando el arte a los espacios públicos habitados por todos y consiguiendo que estas nuevas formas de expresión como el arte urbano estén al alcance de todos.

En el contexto español, en el cual se centrará este artículo, el espacio urbano ha experimentado un notable desarrollo, sobre todo desde comienzos del siglo actual. Gracias a la peatonalización de los centros históricos se ha conseguido recuperar el espacio público necesario para el peatón, con todo lo que ello conlleva; la ciudad se ha convertido en un lugar accesible donde ha comenzado a tener cabida, entre otras cosas, el arte efímero, que ha llegado al medio urbano a través de los grandes y pequeños eventos relacionados con el arte.

El marco geográfico en el que se centran los ejemplos mencionados comprende, entre otras ciudades, Madrid, foco artístico por excelencia y lugar donde, actualmente, se vienen desarrollando más eventos artísticos que en otras ciudades de España.

\section{La arquitectura efímera y la mutación del espacio}

La arquitectura en sí misma tiene un carácter efímero desde que es concebida. Es creada para permanecer en una constante lucha contra el tiempo, el clima o el propio ser humano. Algunas de las obras arquitectónicas creadas tienen una condición más efímera que otras. El limitado tiempo de existencia en este mundo hace de la arquitectura efímera un elemento transformador del espacio donde se ubica. Además de ser una forma de creación que en la actualidad se ha empezado a experimentar de manera más notoria que en los siglos pasados, resulta atractiva porque no requiere de grandes inversiones (Blasco, 2012: 14), y además, el hecho de no tener que ser concebidas para un proyecto a largo plazo, da pie a la prueba de materiales o estructuras nuevas.

\footnotetext{
${ }^{1}$ Boa Mistura es un grupo de artistas madrileños que realizan arte urbano en espacios públicos de distintas ciudades del mundo, contribuyendo, así, a la mejora de los barrios y a la inclusión de los habitantes de las ciudades en estos, como una manera de acercar el arte al mayor público posible. Se pueden consultar sus trabajos en: 〈http://www.boamistura.com/〉
} 
Como se citó anteriormente, las primeras construcciones que pueden ser llamadas “arquitecturas efímeras” se dan en torno a la Edad Media, aunque más en la etapa barroca; sin embargo, en el siglo XIX y principios del XX, se verán también creaciones de carácter efímero, como algunos de los pabellones creados para las Exposiciones Universales ${ }^{2}$, verdaderos hitos arquitectónicos de las últimas décadas (Méndez-Navia, 2015: 11).

Este tipo de arquitecturas efímeras se adaptan fácilmente al espacio, pues al no tener que permanecer en él durante un gran periodo de tiempo, suelen encajar muy bien en el entorno donde son ubicadas. Hoy en día, y como se verá a través de los ejemplos analizados, los artistas contemporáneos dedicados a la arquitectura cada vez recurren más a la de carácter efímero, pues además de ser un medio de experimentación, lo es también de propaganda para sus carreras, y les permite seguir sumando creaciones, aunque sean de carácter temporal, pues aun así serán inmortalizadas a través de imágenes y conocidas, como si de una obra permanente se tratara.

Además de los artistas, las instituciones como los museos, los ayuntamientos o las galerías, han sentido cada vez más predilección por hacer uso de las instalaciones efímeras. Tanto para la promoción de eventos como para fechas señaladas que requieran de algún tipo de creación artística. Y es que la arquitectura efímera tiene la capacidad de reinventar el entorno y de crear preguntas en el espectador que le hacen replantearse la hasta ahora conocida noción de arquitectura.

Estas creaciones efímeras dan lugar a nuevos diálogos con la ciudad y el entorno, y son capaces de interactuar con la sociedad de una manera diferente a la que se venía dando hasta el momento con las distintas formas de expresión artística. La arquitectura efímera resulta relevante en la actualidad, sin olvidar que también fue importante en los siglos pasados. Ha conseguido, a pesar de los cambios que se han desarrollado en el paisaje urbano, heredar el uso que se le daba en otras épocas como en el barroco, cuando las construcciones como las escenografías eran creadas para los festejos del momento, como sucede también hoy en día ${ }^{3}$.

En este artículo se desarrollarán algunos ejemplos que, en los últimos años, han ido teniendo lugar en España, y que demuestran que el arte es capaz de reinventarse, y que la arquitectura

\footnotetext{
${ }^{2}$ Uno de estos pabellones que se construyeron con carácter efímero fue el Pabellón de Alemania para la Exposición Internacional de París en 1937. Asimismo, y como caso más reciente, se podría mencionar también el que construyó Tadao Ando para la Expo92 de Sevilla, el cual fue desmontado una vez concluido el evento, a pesar de ser admirado como una gran obra de arte y que es recordado aunque hayan pasado algunos años.

${ }^{3}$ Con esto se hace referencia a que, en la actualidad, la mayoría de arquitecturas efímeras son creadas para eventos o festejos como La Noche en Blanco.
} 
tradicional como tal ya no es la única que tiene cabida para ocupar el espacio de la ciudad; ha llegado una nueva forma de expresión, y lo efímero toma las calles.

\section{La arquitectura efímera en el medio urbano español}

En nuestro país, sobre todo en los últimos años, el arte efímero ha tomado más presencia en las calles. Artistas emergentes y otros de más prestigio sienten la necesidad de salir del estudio y expresar su arte en la misma ciudad, manteniendo así una relación más directa con el espectador que la que podría darse, por ejemplo, al ubicar la obra en un museo. A continuación se analizarán algunos ejemplos relacionados con la arquitectura efímera que han tenido lugar en algunas ciudades españolas en los dos últimos años.

En 2016 tuvo lugar en Madrid el evento titulado Inflables [1], en el cual, el artista Marco Canevacci y los alumnos de la Escuela Superior de Diseño de Madrid, crearon unas estructuras gigantes, a caballo entre arquitectura y escultura, que fueron instaladas en las inmediaciones de la misma Escuela de Diseño. El proyecto consistía en la intervención del espacio a través de estas instalaciones inflables que creaban reflexiones en el espectador en torno a los conceptos de "lo público" y "lo privado". Estas arquitecturas fueron construidas con un carácter efímero y con la intención de ser habitadas durante el lapso de tiempo de la intervención (Velasco, 2016).

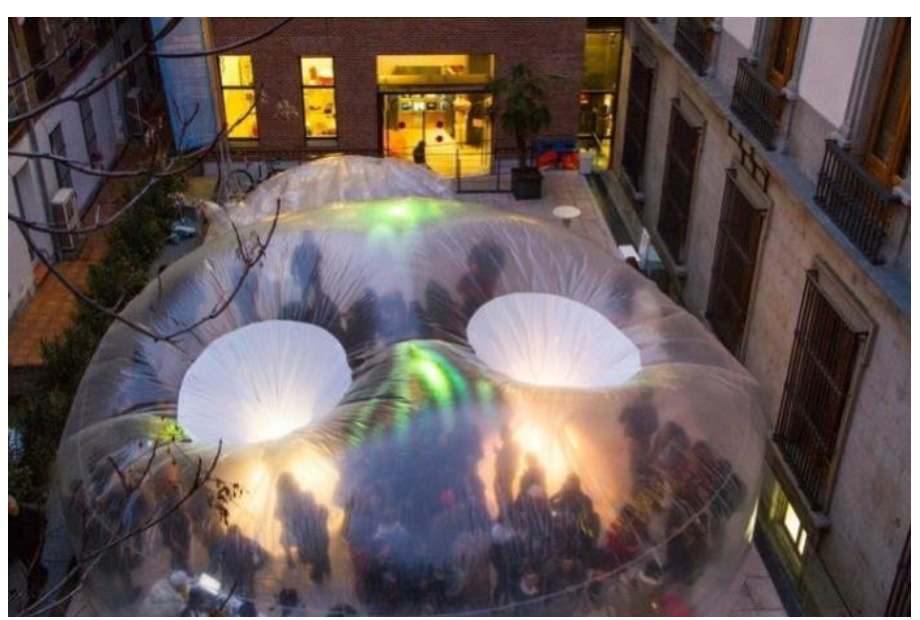

1. Imagen donde se aprecia la arquitectura "inflable" creada por Canevacci. Fuente: domestika.org. 
Con estas creaciones, Canevacci replanteaba la noción de espacio a través de unas estructuras gigantes creadas con materiales ecológicos, que invadieron el entorno durante unos días y que interactuaban con el espectador, que podía habitar dentro de ellas el tiempo que deseara.

A través de propuestas como la de este artista, la sociedad comienza a interactuar cada vez más con el arte; el carácter efímero de las obras resulta, en la mayoría de los casos, más atractivo, pues genera curiosidad en el espectador y le invita a acudir a presenciar lo que acontece.

En otra línea, en el año 2017 fueron instaladas en Logroño una serie de arquitecturas efímeras con el nombre de Concéntrico 03 [2]. Con estas instalaciones, los artistas que crearon las obras pretendían dar su propia visión del centro histórico logroñés a través de las estructuras creadas. Además, se hacía uso de la tecnología, pues algunas de las piezas eran alumbradas por la noche con luces led, creando efectos cromáticos que transformaban la visión del espacio. Las creaciones realizadas fueron un total de 9, que, durante unos días, convivieron con los habitantes de Logroño, siendo ubicadas en el Casco Histórico de la ciudad e interactuando con el viandante.

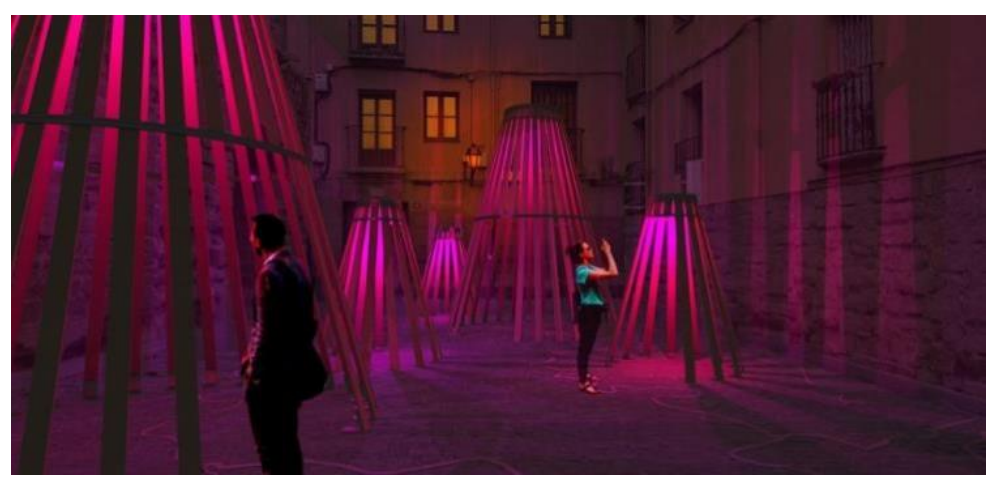

2. Una de las obras de "Concéntrico 03" ubicada en el Centro Histórico de Logroño. Fuente: metalocus.es

El mismo año 2017, los estudiantes de arquitectura de la Universidad de Málaga realizaron una intervención efímera que fue situada en las inmediaciones del Muelle Uno [3]. El proyecto se enmarcó dentro de La Noche en Blanco de la ciudad, y se presentó como una obra que trasladaba al espectador a un mundo onírico, donde también estaban presentes las iluminaciones led. A través de unos tejidos de color blanco, acompañados de luces, música y otros tipos de sensaciones, los creadores de la obra consiguieron despertar un interés por el arte efímero en el visitante. Es frecuente encontrar este tipo de intervenciones dentro de las iniciativas artísticas como La Noche en Blanco. 
Sin ir más lejos, este año, los mismos alumnos de arquitectura de la UMA han realizado otro proyecto basado en la arquitectura efímera situado en el mismo espacio que el mencionado con anterioridad. Se trataba de una instalación de carácter efímero que se inspiraba en la relación entre la figura femenina y la arquitectura, y que invadía el espacio a los pies del Puerto de Málaga para ofrecer una experiencia donde los colores tomaban el protagonismo, y donde nuevamente, con un lapso de tiempo de unas horas, creaba sensaciones diferentes a las transmitidas por la arquitectura tradicional.

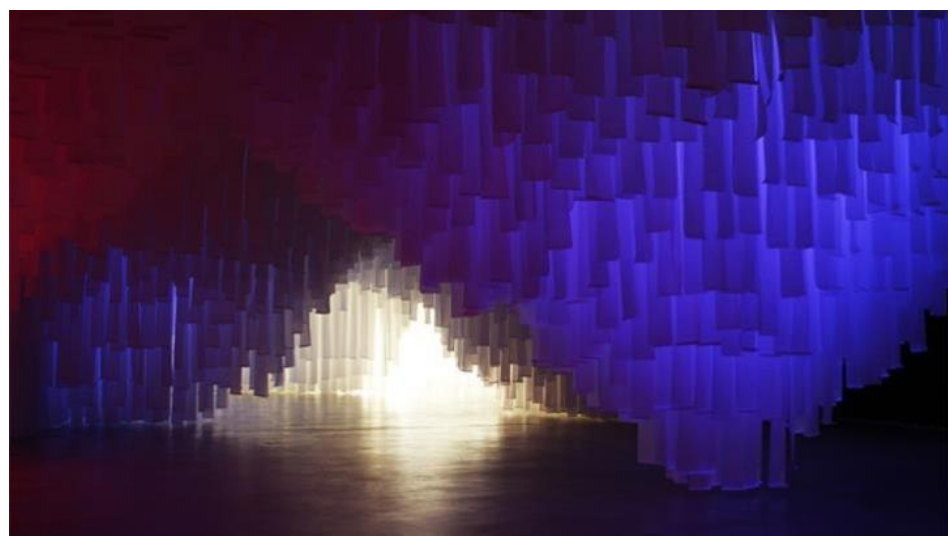

3. Arquitectura efímera creada en 2017 por alumnos de la Universidad de Málaga. Fuente: arquinfad.org

Este mismo año también, y volviendo a la ciudad de Madrid, ha tenido lugar Pinta Malasaña [4], un festival de arte urbano donde la arquitectura era vestida ${ }^{4}$ de manera efímera. Más que de una instalación, en este certamen se podría hablar más de intervención mural. Numerosos artistas tomaron las calles para decorar fachadas, escaparates y todo tipo de elementos arquitectónicos. Se transformaba el entorno, aunque de una manera diferente a la vista hasta el momento. Era una invasión del espacio también por parte del cuerpo, pues los propios artistas, durante las horas que duraba el festival, salían a la calle a pintar esa arquitectura.

El espacio público se convertía, así, en un lienzo en blanco para numerosos artistas urbanos que veían en las construcciones arquitectónicas de la ciudad una oportunidad para expresarse. Es un concepto diferente de arquitectura efímera, pues aquí se fusiona también el arte urbano; pero, al igual

\footnotetext{
${ }^{4}$ Se habla del término "arquitectura vestida" para hacer referencia a los actos en los que se interviene las fachadas, ventanas y demás elementos, como en el ejemplo mencionado.
} 
que los ejemplos anteriores, Pinta Malasaña ${ }^{5}$ tuvo la misma capacidad de transformación del entorno, fusionando también la creación con la música en directo y otro tipo de actividades.

Sin duda alguna, son numerosos los ejemplos de arquitectura efímera que últimamente están teniendo lugar en las ciudades españolas. Intervenciones cada vez más necesarias para tomar las calles y ocupar un espacio que pide ser habitado y revitalizado.

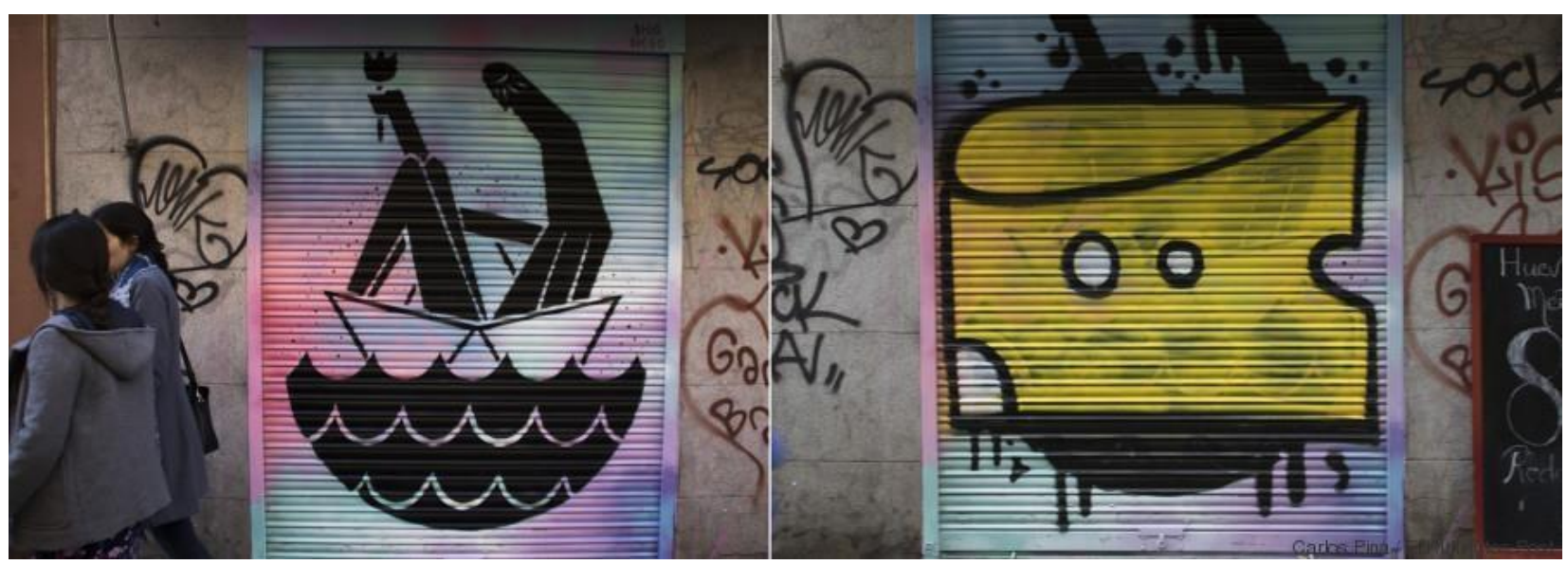

4. Muestra de fachada pintada dentro del certamen Pinta Malasaña.

Fuente: huffingtonpost.es

\section{Conclusiones}

Tras haber hecho un recorrido por la arquitectura efímera y el desarrollo del entorno urbano como soporte para ésta, se puede llegar a la conclusión de que, hoy en día, es necesario regenerar el espacio que nos rodea. El arte tiene la capacidad de transformar todo a su paso, y se ha demostrado que el arte efímero tiene la cualidad de hacer esas transformaciones de una manera más asequible y accesible que las formas de creación tradicionales.

En el caso de las arquitecturas efímeras, se ha podido comprobar que, una vez instaladas, son capaces de cambiar la noción de entorno que hasta el momento se tenía, y que son necesarias para crear reflexiones en el espectador que le lleven a plantearse la idea de arte, la idea de arquitectura y, por supuesto, la idea de ciudad no solo como máquina habitable.

\footnotetext{
${ }^{5}$ Se trata de un certamen multidisciplinar que tiene lugar a finales de abril en la ciudad de Madrid. Además de realizarse intervenciones murales, se hacen performances, conciertos, etc.
} 
Ahora es necesario que se sigan desarrollando los eventos artísticos de carácter efímero para, poco a poco, conseguir que la sociedad se vaya acercando cada vez más al arte sin sentirse invadidos, sino creando una sensación de necesidad para que acabe siendo algo esencial en la vida de las personas. Y es que, como dijo Oscar Wilde, "la vida imita al arte mucho más que el arte imita a la vida"i.

\section{Referencias bibliográficas}

BLASCO RODRÍGUEZ, CARMEN (2012), "Efímeras: alternativas habitables", en Pasajes arquitectura y crítica, $\mathrm{n}^{\circ} .124$, p. 14.

BRAINY QUOTE, En: <https://www.brainyquote.com/es/citas/oscar-wilde_163190> (Consulta: 16/07/2018).

HERMOSO CUESTA, Miguel (2004), “Apuntes sobre Luca Giordano y el arte efímero”, en Artigrama, no. 19, p. 139.

MÉNDEZ-NAVIA GARCÍA, VEGA, "Lo permanente en lo efímero. Pabellones de exposiciones universales, hitos de la arquitectura de la segunda posguerra". En: 〈https://goo.gl/8C7VTW> (Consulta: 18/08/2018).

VELASCO, ELENA, “Plastique Fantastique! O cómo disfrutar de una experiencia espacial en Madrid”. En: <https://goo.gl/b6Apo5> (Consulta: 20/07/2018)

$\overline{{ }^{\mathrm{i}} \text { En: 〈https://www.brainyquote.com/es/citas/oscar-wilde_163190> }}$ 